\title{
Subsidence monitoring system for offshore applications: technology scouting and feasibility studies
}

\author{
R. Miandro ${ }^{1}$, C. Dacome ${ }^{1}$, A. Mosconi ${ }^{2}$, and G. Roncari ${ }^{2}$ \\ ${ }^{1}$ ENI SpA - Geodynamics department, via del Marchesato, 13, 48100 Marina di Ravenna, Ravenna, Italy \\ ${ }^{2}$ ENI SpA - Geodynamics department via F. Maritano, 26, 20097 San Donato Milanese, Milan, Italy
}

Correspondence to: R. Miandro (roberto.miandro@eni.com)

Published: 12 November 2015

\begin{abstract}
Because of concern about possible impacts of hydrocarbon production activities on coastal-area environments and infrastructures, new hydrocarbon offshore development projects in Italy must submit a monitoring plan to Italian authorities to measure and analyse real-time subsidence evolution. The general geological context, where the main offshore Adriatic fields are located, is represented by young unconsolidated terrigenous sediments. In such geological environments, sea floor subsidence, caused by hydrocarbon extraction, is quite probable. Though many tools are available for subsidence monitoring onshore, few are available for offshore monitoring. To fill the gap ENI (Ente Nazionale Idrocarburi) started a research program, principally in collaboration with three companies, to generate a monitoring system tool to measure seafloor subsidence. The tool, according to ENI design technical-specification, would be a robust long pipeline or cable, with a variable or constant outside diameter (less than or equal to $100 \mathrm{~mm}$ ) and interval spaced measuring points. The design specifications for the first prototype were: to detect $1 \mathrm{~mm}$ altitude variation, to work up to $100 \mathrm{~m}$ water depth and investigation length of $3 \mathrm{~km}$. Advanced feasibility studies have been carried out with: Fugro Geoservices B.V. (Netherlands), D’Appolonia (Italy), Agisco (Italy).

Five design (using three fundamental measurements concepts and five measurement tools) were explored: cable shape changes measured by cable strain using fiber optics (Fugro); cable inclination measured using tiltmeters (D'Appolonia) and measured using fiber optics (Fugro); and internal cable altitude-dependent pressure changes measured using fiber optics (Fugro) and measured using pressure transducers at discrete intervals along the hydraulic system (Agisco). Each design tool was analysed and a rank ordering of preferences was performed. The third method (measurement of pressure changes), with the solution proposed by Agisco, was deemed most feasible. Agisco is building the first prototype of the tool to be installed in an offshore field in the next few years.

This paper describes design of instruments from the three companies to satisfy the design specification.
\end{abstract}

\section{Introduction}

Ente Nazionale Idrocarburi Upstream \& Technical Services, as other companies involved in hydrocarbon exploration and production in Italy, especially for the offshore fields located in the central-northern Adriatic Sea, must submit a monitoring plan to Italian authorities to measure and analyse realtime subsidence evolution before any oil or gas production. The monitoring plan must address foreseeable impacts, direct or indirect, of hydrocarbon production on coastal areas and in the adjacent inlands.
The general geological context, where the main offshore gas field are located, is represented by young unconsolidated terrigenous sediments, partially still forming and most of the surrounding coastal lands have general heights below medium sea level, up to $-5 \mathrm{~m}$. In such geological environments, the subsidence, potentially caused by hydrocarbon production, has to be managed. If part of the produced subsidence cone or "bowl" extends to the coast, it can cause geologic and environmental hazard, costly third party claims and damage to the company's public image. 


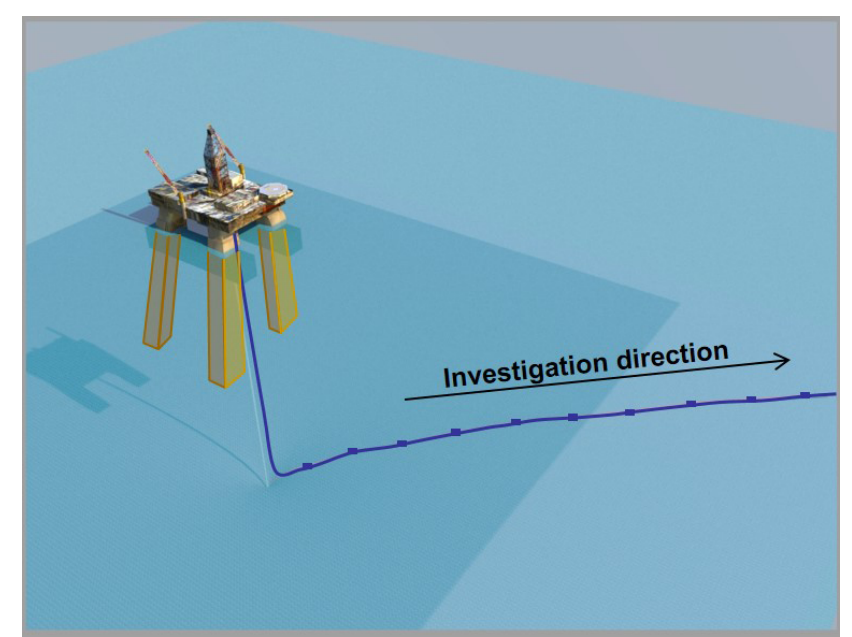

Figure 1. Sketch of cable-based subsidence monitoring system.

Though many tool are available for subsidence monitoring onshore, few are available for offshore monitoring. Therefore, in 2010 ENI, aiming to assure stakeholders that hydrocarbons in the offshore fields could be produced with no impacts on the coastal areas and on the region's subsidence trend, initiated a research program with three companies, to develop a monitoring system tool to measure seafloor subsidence.

The tool, according to ENI technical-specifications, would be a robust long pipeline or cable (cable based subsidence monitoring system - Fig. 1), with a variable or constant outside diameter (OD, less than or equal to $100 \mathrm{~mm}$ ) with regularly spaced measuring points.

The design device would detect and measure seafloor movements along its deployment direction and provide temporal seafloor altimetrical variations $(1 \mathrm{~mm})$, measured at discrete points along the cable.

To let, each of the involved companies in the feasibilities tasks, better understand the size and extension of the subsidence that was expected to be monitored, they were provided with ancillary information from a subsidence case, registered and monitored in the Italian offshore (Figs. 2, 3). The subsidence case, monitored through a multibeam echosounder (MBES) survey, showed an anomaly in the bathymetry at water depths of about 20 and $25 \mathrm{~m}$ (Fig. 2). The isolated subsidence bowl (Fig. 3), extends nearly $3 \times 5 \mathrm{~km}$, with a maximum depression of nearly $80 \mathrm{~cm}$. The GPS station, placed on the production platform, showed a subsidence velocity of about $35 \mathrm{~mm}$ each year. Geo-mechanical modelling results for this case, indicate a subsidence rate of about $15 \mathrm{~mm} \mathrm{a}^{-1}$ approximately $2 \mathrm{~km}$ distant from the bowl centre. The companies were requested to monitor subsidence as a function of time and location, with a vertical accuracy of $1 \mathrm{~mm}$ in real time.

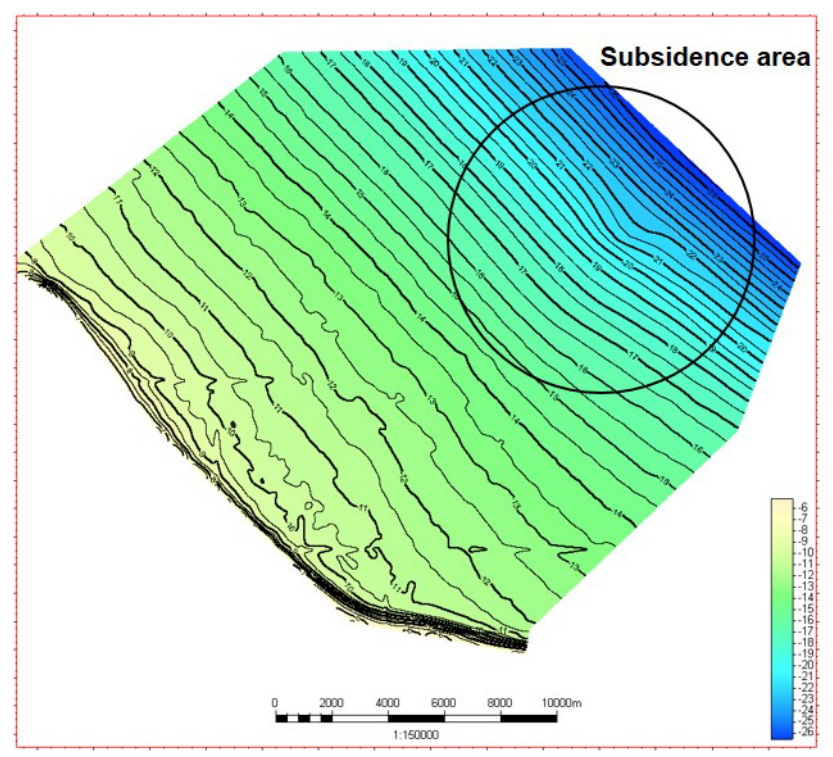

Figure 2. Subsidence case.

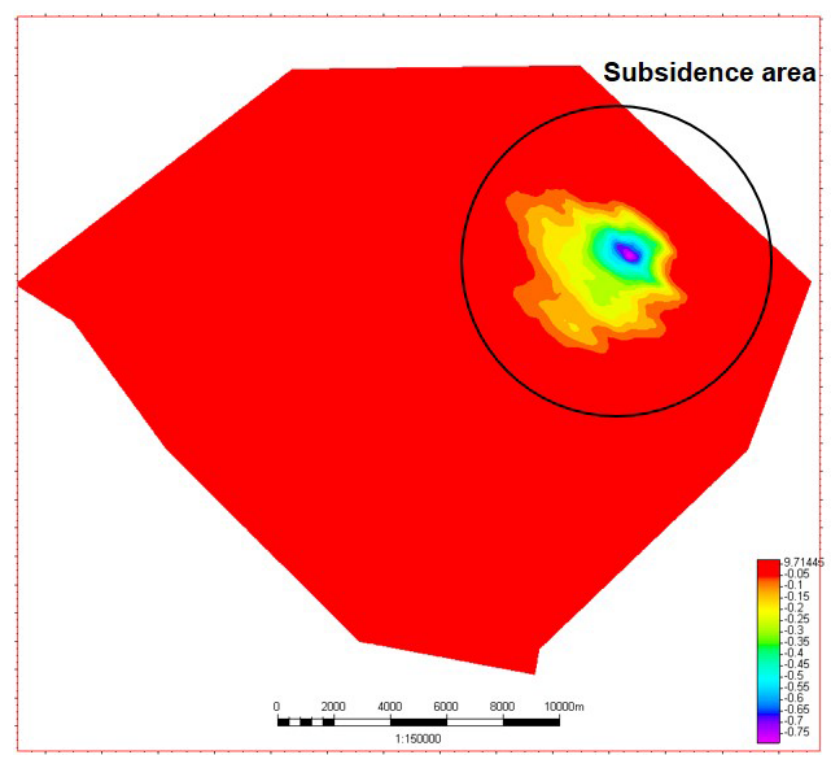

Figure 3. Isolated subsidence "bowl".

Three companies were asked to perform advanced tooldevelopment feasibilities studies: Fugro Geoservices B.V. (The Netherlands); D'Appolonia (Genova, Italy); Agisco (Liscate (MI), Italy). In addition, to the expected subsidence case above, the companies were provided with the following technical specifications and constraints:

- Cable working condition up to $100 \mathrm{~m}$ water depth (ca. $1 \mathrm{MPa})$.

- Cable OD preferably not over $100 \mathrm{~mm}$.

- Maximum tool length: $3 \mathrm{~km}$. Modular cable system, extendable in length, was preferable. 
- Maximum distance among discrete measurement points between 100 and $200 \mathrm{~m}$.

- Measurement of altitude (z)-changes vs time $(\mathrm{d} z / \mathrm{d} t)$. Absolute cable $z$ position not required.

- Only cable vertical movements, downward or upward, envisaged.

- The cable had to be placed in a trench about $1 \mathrm{~m}$ below the sea floor and subsequently covered with soil material. The soil material fixed the cable position integral to the soil.

- Possible to reference one cable end to a point with known movement (CGPS on platform).

- Data acquisition unit and electronics to be placed on board the production platform.

- Monitoring system lay-out geometry comprises segments aligned with the most critical direction of the subsidence bowl, from maximum toward minimum with a fixed offshore platform resting on legs.

- Monitoring for a minimum period of 10 years after installation.

\section{Fugro proposed tool}

Fugro conducted a feasibility study, in collaboration with the Netherlands Organisation for Applied Scientific Research (TNO), of a cable-based subsidence monitoring system equipped with fiber optic sensors.

The choice for fiber optic sensors was based on high accuracy, ease of data multiplexing and most importantly, the absence of electronics in a Fiber Optic Monitoring Cable (FOMC) (Measures, 2001).

After a preliminary inventory of requirements, three fiber optic based measurements concepts different concepts were generated:

1. Cable shape determination through strain measurement (Fig. 4).

I. The shape of a cable and the deformation of the shape can be determined using fiber optic sensors that measure the changes in strain $\varepsilon$ at a certain distance $r_{\mathrm{f}}$ from the neutral line of the cable, the strain at a specific location $x$ and time $t, \varepsilon(x, t)$, is sampled at spatial interval $\Delta x$. In this technique subsidence of the cable along its length at any time, $s(x, t)$, can be reconstructed from the measured deformation of the cable.

II. Several fiber optic methods exist to measure the local strain $\varepsilon$ in the cable:

i. Fiber Bragg Gratings (FBG).

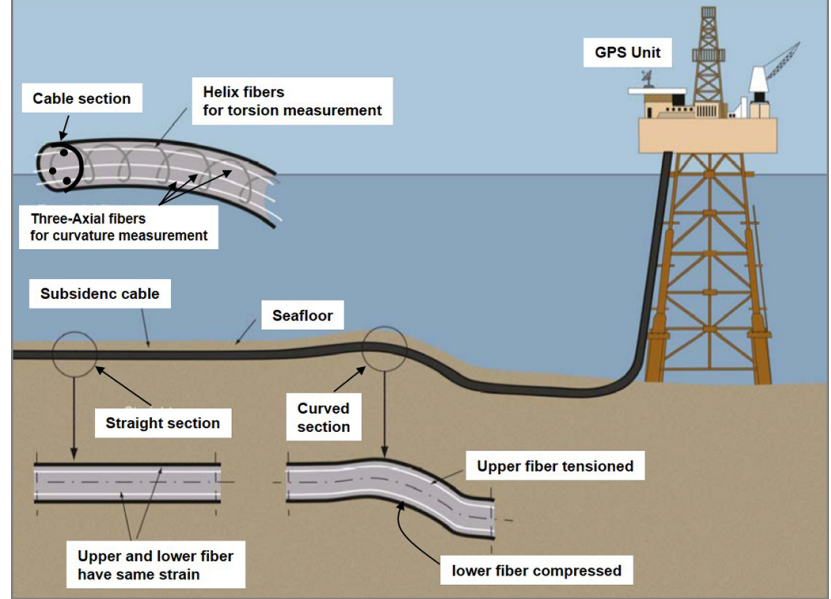

Figure 4. Schematic overview of subsidence measurement using strain measurement.

ii. Distributed strain sensing using Raman or Brillouin scattering (known as DTS).

iii. Fiber interferometry.

III. For this measurement concept (1), exact knowledge of the cable orientation is essential. This can be achieved by using:

i. A cylindrical cable that could torque during the production process and/or when the cable is placed in the trench on the sea-bottom followed by a very accurate determination of this torque, or

ii. An oblate cable of which the orientation can be kept constant during production and during placement.

2. Cable inclination measurement (Fig. 5)

I. When part of the cable moves in a vertical direction the inclination of the part just before and just after the moving part of the cable will change.

II. Different options exist to measure this change of inclination through fiber optic sensors.

3. Pressure measurement (Fig. 6)

I. When part of the cable moves in a vertical direction the pressure in this part of the cable will change relative to the pressure in other parts of the cable.

II. Different options exist to measure these pressure changes via fiber optic sensors.

For each measurements concept, feasibility studies determined that in theory, the required accuracy could be achieved by each of these concepts, however the steps required to develop a prototype system for each concept differed. Subsequently an inventory of the failure risks was made, followed 


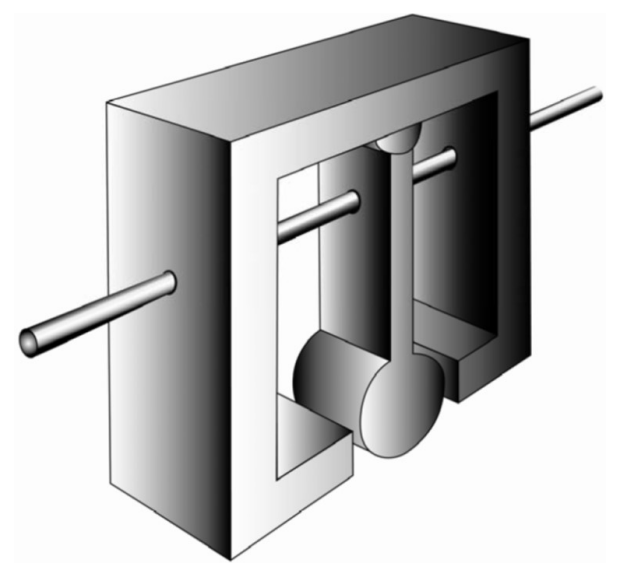

Figure 5. Schematic overview of an inclinometer based on a pendulum $p$. The pendulum can only rotate over an angle $\alpha$ along an axis perpendicular on the drawing. The rotation $\alpha$ of this pendulum is measured with optical fibers.

by a preliminary evaluation of each risk. Some risks were considered acceptable, for others, additional development studies were deemed necessary to avoid unacceptable failures. The required development process, determined through technology readiness level (TRL) analysis, was greatest for strain measurements and least for pressure measurements.

In addition to the TRL analysis above, in order to find a trade off among the different measurement concepts, the concepts were compared on a number of different aspects, like, for instance: measurement accuracy; development (risks, time, costs); capex (sensor and cable production, cable deploy, electronic); opex (maintence, calibration, etc.); modularity, etc. (only aspects that were expected to be different for the different concepts were compared). This comparison resulted in favour of pressure measurement in a liquid filled tube as a preferred concept, followed by inclination and strain. The final conclusion was to proceed with a test phase, building a demonstration system, based on fiber optic pressure measurements in a liquid filled cable.

\section{D'Appolonia proposed tool}

D'Appolonia conducted its feasibility study for a system to monitor seafloor subsidence performing the following tasks:

- Review of available methods.

- Technology review.

- Analysis of scientific literature and patents.

- Description of theoretical cases for system definition and methods selection.

- Assessment of the following selected two methods:

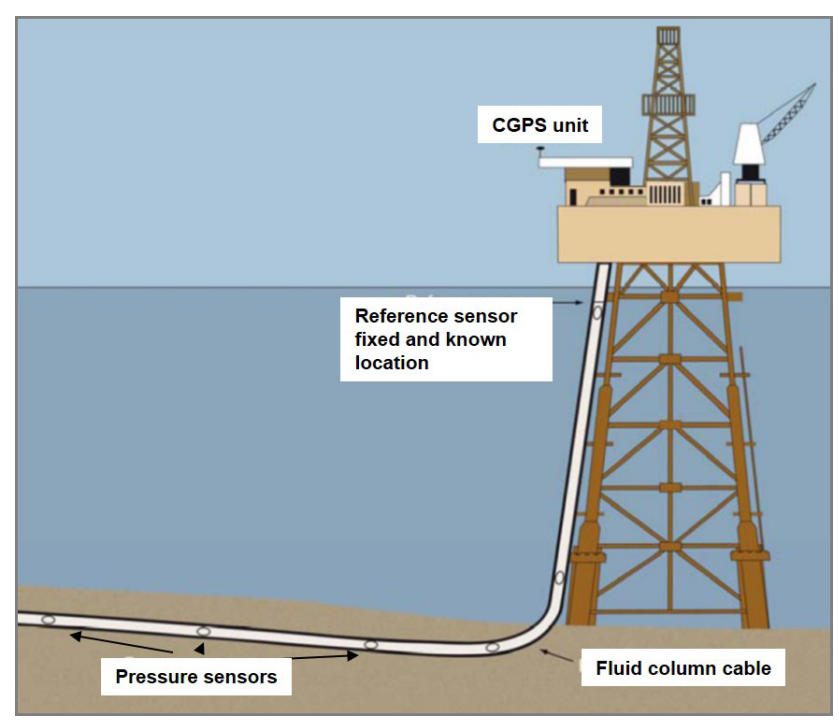

Figure 6. Schematic overview of subsidence measurement via pressure measurement in a liquid filled cable. The cable is open at one end and is filled with a liquid. The small ellipses in the cable denote the pressure measurement positions. The vertical position of the platform is continuously monitored with GPS equipment.

a. Measurement of the seafloor inclination by means of an array of tiltmeters, and integration of the tilt over distance to obtain the vertical displacement.

b. Measurement of the differential pressure along a pipe, decoupled from the external pressures, provided with high-precision pressure gauges at suitable spacing.

The first method has been used onshore and offshore (Anderson et al., 1997; Fabian and Villinger, 2007), the second method is in a development stage for offshore applications (Mes, 1989; Stenvold et al., 2006). The first method was considered the most promising and was further developed. The feasibility study was therefore continued focusing on the measuring of the altimetrical sea floor variation through tiltmeter arrays.

The further following tasks were performed:

- Evaluation of subsidence at an offshore pilot site, and confirmation of the suitability of a tiltmeter-based system to measure offshore subsidence.

- Definition of tiltmeter system requirements.

- Selection of an "off-the-shelf" tiltmeter with respect to the specified requirements, and verification of its performance in the laboratory.

- Design and modification of the tiltmeter for this application, and design of a complete system with all the needed components. 


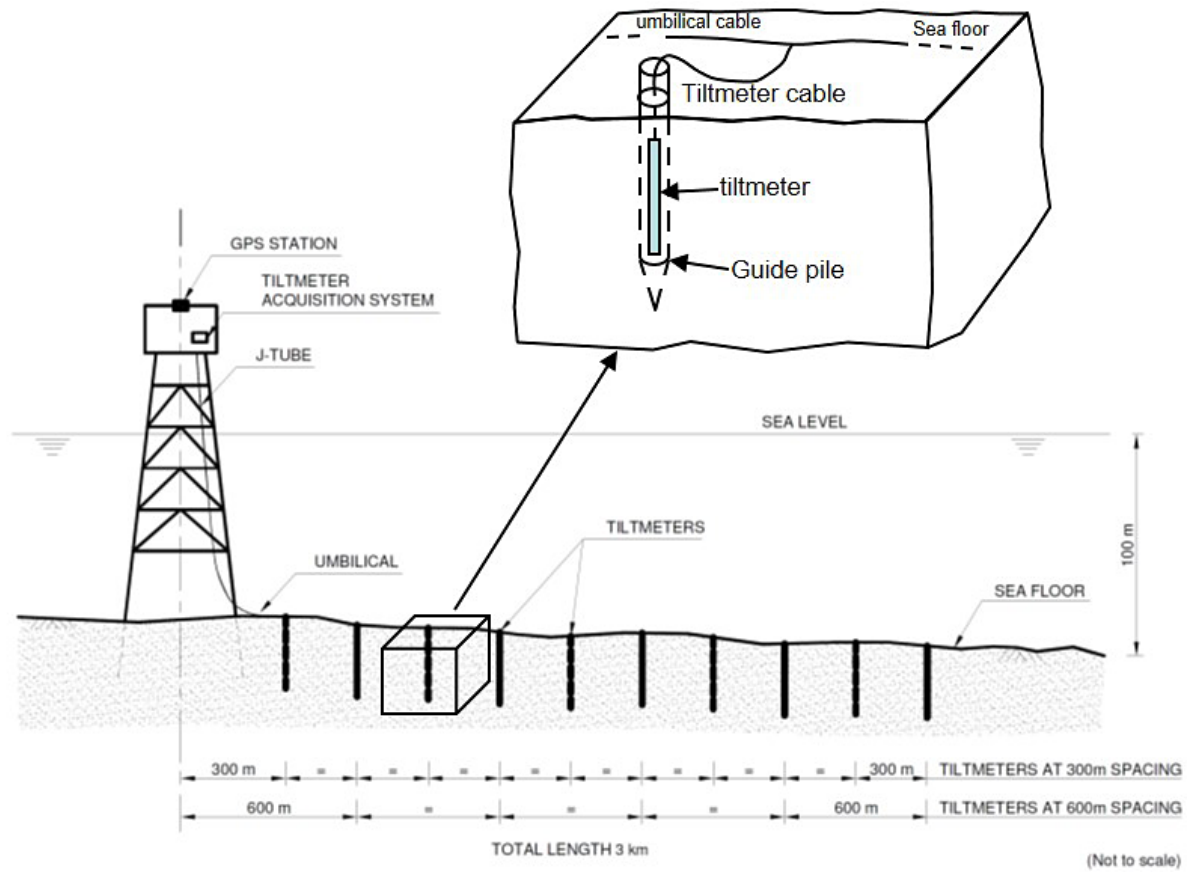

Figure 7. D’Appolonia system layout.

A generalized layout of a complete system it is shown in Fig. 7. It included the following parts:

- GPS station for the measurement of vertical displacement of the platform (Setan and Othman, 2006). GPS is already present on all ENI's platforms.

- J-tube for the umbilical.

- Array of tiltmeters fixed to the seafloor at a predetermined direction and spacing.

- Umbilical cable, including electrical wires and strong rope, connecting the tiltmeters to the data acquisition system installed on the platform.

Design of system component like: tiltmeter, guide pile (for tiltmeters installation), tiltmeter cable, umbilical cable were also provided.

Finally the requirements for offshore installation were as well investigated. In particular this part evaluated the:

- Optimal direction to deploy tiltmeter array.

- Platform characteristics.

- Necessary pre-installation bathymetric surveys of the site.

- Protective measure for the system.

- Installation procedures for the system.

At the end of the study D'Appolonia stated to be ready for the production of working system.

\section{Agisco proposed tool}

Agisco is a long-standing experienced ENI's contractor, that cooperated with ENI since the beginning of the 90's, providing all the customized equipments for the soil shallow compaction monitoring of the onshore Adriatic coast. Agisco, is a qualified company in design, installation and implementation of geotechnical measurement instrumentation for monitoring soil, subsoil and civilian works.

Agisco did not produce a feasibility study but proposed enhancing an existing proprietary tool, already successfully used to monitor possible horizontal bending of dams, harbours and airport runways. The measuring principle of the proposed tool was based on the measurement of the pressure in a column of a liquid acting on several measuring points. The device used pressure sensors to measure the relative vertical displacement of these points with respect to a reference point. The displacement between two sensors was obtained from the proportional relation between the pressure difference and displacement. The theoretical scheme of the devices, included: a reference tank, a hydraulic circuit and one or more measuring points. The main problem with the existing tool is that it is open to the atmosphere, condition difficult or even impossible to achieve underwater. This problem could be overcome by using a "closed" circuit, isolated from the atmosphere.

Therefore, Agisco proposed to redesign the existing tool. The new design had to take into account all the related problems of underwater deployment and also consider a different tool shape and sturdier structure, allowing a safe, se- 
cure, failure-free tool installation at the specific water depth $(100 \mathrm{~m})$. In fact, feasibility of off-shore tool installation, is significant at least from the economical point of view.

The proposed "submarine hydraulic profile gauge" using the pressure measurement principle and a "closed" hydraulic circuit was selected for further developmental evaluation. The design was quite challenging and time consuming, requiring a number of tests to verify the suitability of alternative solutions for the closed hydraulic circuit. The best solution was the use of a "compensator" (Fig. 8) which is the real core and innovation of Agisco's proposed system, which is covered by patents in the European Union and in the United States of America. The concept of the compensator is that it has to allow for volume changes of the liquid when no real changes in the altitude of the hydraulic circuit and when altitude-dependent pressure changes occur. Source of altitude-independent volume changes could be thermal liquid expansion, shocks or hose squeezing. Moreover "shockwave" could be induced into the circuit during installation and/or maintenance operations. Pressure changes induced by volume changes or shock-waves may be very high and damage the pressure transducers, therefore they had to be efficiently limited.

The design of the compensator was developed in parallel with the research on two other key issues which characterize a hydraulic device: (1) the hydraulic fluid selection and (2) the thermal compensation.

The research led to the final configuration which enables use one of a single compensator for each circuit.

The liquid to be used in hydraulic profilers had to meet with some critical specifications:

- Stable properties during the measuring or monitoring time period (10 years at least).

- Air-free (no gas bubbles) during the device life time. Gas can modify tool response time and change the circuit pressure.

- Known density and temperature-dependent density relation with high accuracy. Small changes in density cause significant variation in measured pressure and therefore in system accuracy.

- No microbial growth to avoid gas production and change in density.

In order to select the best liquid, a comprehensive research effort has considered a large selection of possible liquid and blends. A number of different mixtures have been tested and their physical characteristics have been investigated and quantified.

Final attention has been focusing on water-glycol mixtures, which have low freezing point and good stability. Laboratory test results, performed on different blends, are being used to derive temperature-dependent density relationship, one of the most important and critical parameters.

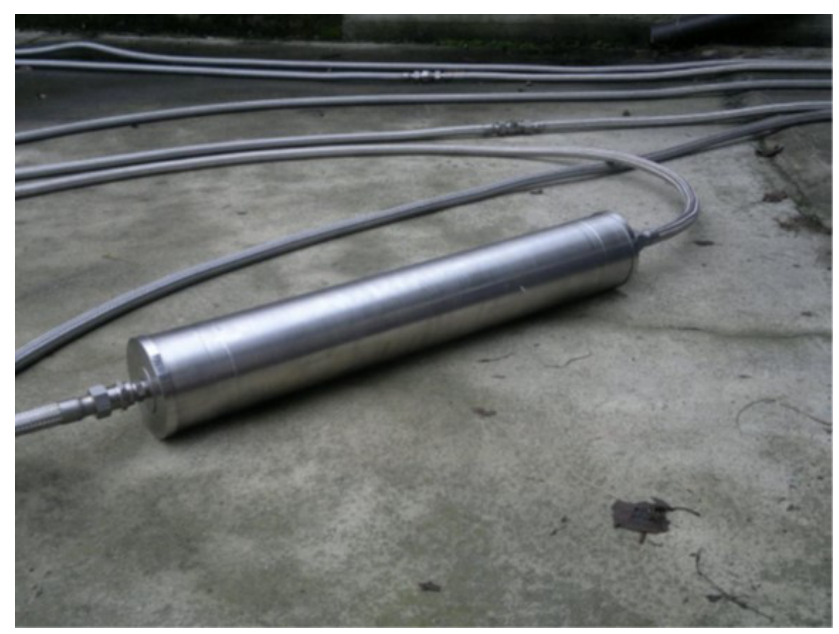

Figure 8. Agisco compensator.

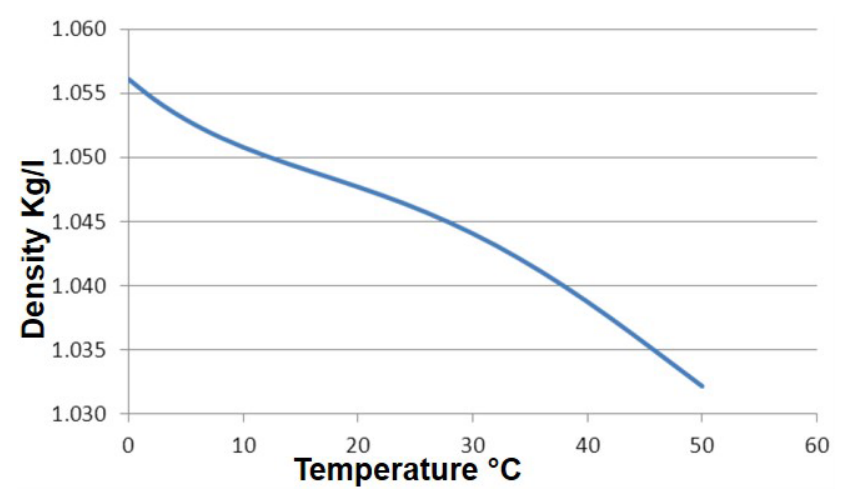

Figure 9. Liquid density vs. temperature relationship.

The results showed that liquid density changes nonlinearly with temperature (Fig. 9), the relationship has been derived starting from the reference equation by F. J. Millero and A. Poisson (Millero and Poisson, 1981). This is one of the key results, which have been used to "compensate" pressure measurement along the circuits. For off-shore application it is not so critical unless (a) the circuit is crossing water layers at different temperature or (b) part of the circuit is onshore or outside (the reference) and part is offshore (the measuring points); or (c) the offshore circuit is in shallow water, where significant temperature changes occur owing to daily and seasonal climatic conditions.

The design of the compensator needed to take into account the thermal effects and it has been studied using a specific array of thermometers embedded in the hydraulic circuits enabling measurement of the temperature distribution. Thus, the temperature profile along the whole circuit could be determined and the density of the liquid calculated to process the pressure signals. After study and selection of the two key items - liquid and temperature and compensa- 
tion method, other important aspects have been studied and solutions adopted about the following system components:

- Pressure transducers.

- Hose.

- Enclosure.

- Signals.

- Cables.

- Data Acquisition Unit.

- Processing Software.

Among these, the most important item has been the pressure transducer selection. Hydraulic profilers use both absolute and differential pressure transducers. It was decided to use absolute pressure transducer to avoid the need for an equalized reference-pressure and considering that the circuits are closed.

The main specifications used as reference were:

- Robustness, because deployment had to be managed by cranes and operated by offshore devices.

- High stress tolerance to survive installation shocks and accommodate large differences in relative elevation.

- High accuracy enabling 1-10 mm overall accuracy of the device.

- Low temperature sensitivity to reduce thermal effects.

- Negligible volume change to minimize the effect on the circuit volume and to avoid liquid movement.

- High zero and high scale stability for long term monitoring.

- Enhanced output signal stability.

- High reliability to cope with long term monitoring.

- Compatibility with the hydraulic liquid.

Various pressure transducers that purportedly met the specifications were tested. The selected transducers were the piezoresistive type with a $100-500 \mathrm{kPa}$ measuring range and digital output with a 20 bit analog to digital (A/D) converter. A digital output was specified for the following main reasons:

- Possibility to use a MOD-BUS transmission protocol on a single cable.

- Possibility to set the temperature compensation parameters directly inside the transducer to obtain compensated signals.

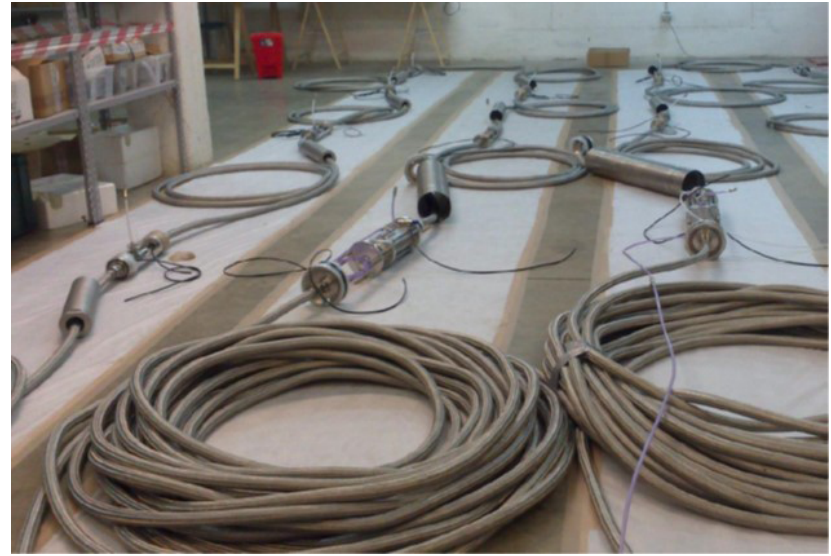

Figure 10. Configuration of profile prototype.

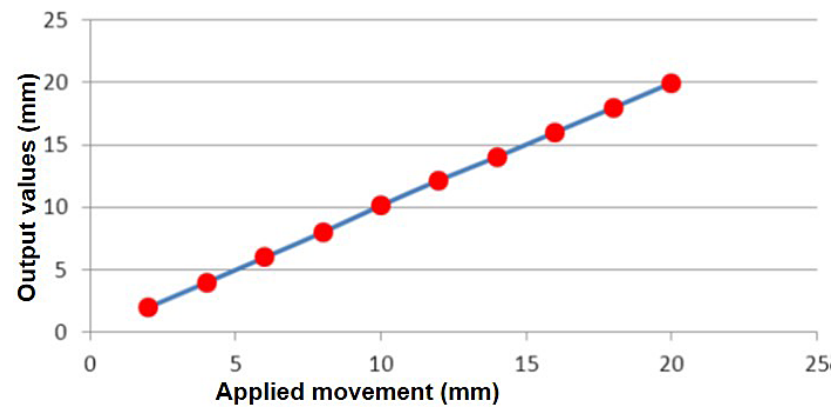

Figure 11. Calibration Sheet for measuring point.

- Possibility to use a standard 485 serial output, whose low bit rate allows long distance transmission, up to $3 \mathrm{~km}$.

- Easy dynamic data acquisition.

Finally Agisco was able to produce a first prototype of the Horizontal Hydraulic Profile Gauge. The current configuration of the profiler is shown in Fig. 10 where the measuring points, the circuit and the compensator are presented.

The main specifications of the prototype tool are:

- Measuring range: up to $100 \mathrm{~m}$ water depth.

- Resolution: $\pm 0.05 \%$ F.S.

- Number of measuring points: up to 128.

- Length: standard: 500+ m; extended: $4 \mathrm{~km}$.

- Degree of protection: Ingress Protection rating of IP69 K-1 MPa.

- Certifications: European Conformity (CE).

Typical results from laboratory calibration (performed by using calibrated shims) is shown in Fig. 11. 


\section{Conclusions}

The offshore subsidence, being underwater, is usually less impacting on local coastal environments and communities and consequently less studied and with fewer tools available, for monitoring. The present work allowed ENI to explore offshore subsidence monitoring. Researching the available technology allowed an in-depth analysis of the technological opportunities in all technical fields relevant to monitoring of seafloor subsidence. The research included assessing patents/industrial property rights and the scientific and technical literature.

But, above all, feasibility studies allowed establishment of the basis to build a working tool to be used for offshore applications in subsidence monitoring. Different monitoring challenges and approaches were identified based on different measurement concepts and devices, fiber optics for measuring strain, tiltmeters for measuring tilt and a closed hydraulic system with pressure transducers for measuring differential pressures. The first two concepts were promising and challenging, but the solution proposed by Agisco for measuring differential pressure in a closed hydraulic system was deemed a more sufficiently proven technology that required minor modification to an existing proven design in order to be adapted for offshore use. Agisco is producing a working prototype tool during 2015 and ENI plans to deploy an offshore installation of the tool within the next few years.

\section{References}

Anderson, G., Constable, S., Staudigel, H., and Wyatt, F. K.: A Seafloor Long-Baseline Tiltmeter, J. Geophys. Res., 102, 2026920285, 1997.

Fabian, M. and Villinger, H.: The Bremen ocean bottom tiltmeter (OBT) - a technical article on a new instrument to monitor deep sea floor deformation and seismicity level, Mar. Geophys. Res., 28, 13-26, doi:10.1007/s11001-006-9011-4, 2007.

Measures, R. M.: Structural Monitoring with Fiber Optic Technology, Academic Press Inc, San Diego, California, USA, Chapters 5, 6, 7, 716 pp., 2001.

Mes, M. J.: Accuracy of Offshore Subsidence Measurements with Seabed Pressure Gauges", 21st Annual Offshore Technology Conference, 1-4 May 1989, Houston, Texas, USA, Paper No. 6063, 213-222, 1989.

Millero, F. J. and Poisson, A.: International one-atmosphere equation of state of seawater, Deep-Sea Res. Pt. I, 28, 625-629, 1981.

Stenvold, T., Eiken, O., Zumberge, M. A., Sasagawa, G. S., and Nooner, S. L.: High-Precision Relative Depth and Subsidence Mapping from Seafloor Water-Pressure Measurements, Journal of the Society of Petroleum Engineers, Paper No. SPE 97752, 380-389, 2006. 